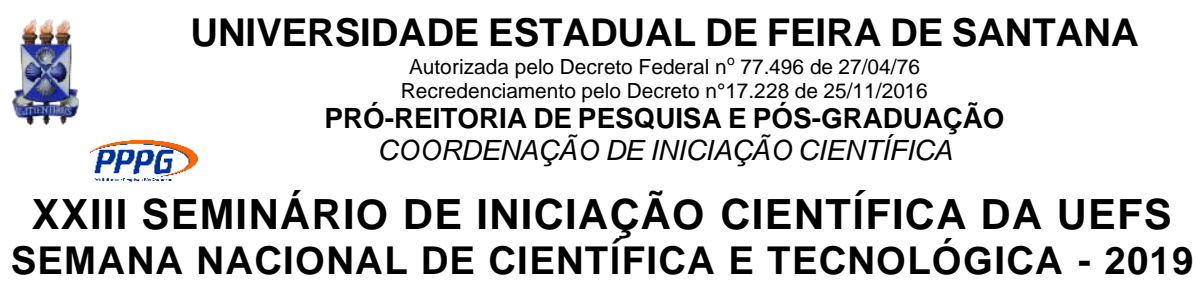

\title{
Controle alternativo de pragas em quiabeiro (Abelmoschus esculentus) utilizando extratos vegetais de Nim (Azadirachta indica).
}

\author{
Thales A. Pinheiro1; Éverton Souza da Silva²; Janete J. Resende ${ }^{3}$ e Jucelho Dantas da \\ $\mathrm{Cruz}^{4}$ \\ 1. Bolsista PROBIC/UEFS, Graduando em Agronomia, Universidade Estadual de Feira de Santana, e-mail: \\ thales.apwork@gmail.com \\ 2. Graduando em Agronomia, Universidade Estadual de Feira de Santana, e-mail: jjresende@uefs.br \\ 3. Participante do projeto, Departamento de Biologia, Universidade Estadual de Feira de Santana, e-mail: \\ vertosouza2@gmail.com \\ 4. Orientador do projeto, Departamento de Biologia, Universidade Estadual de Feira de Santana, e-mail: jucelho@uefs.br
}

\begin{abstract}
PALAVRAS-CHAVE: Abelmoschus esculentus; Bioinseticida; Azadirachta indica; Agricultura familiar.
\end{abstract}

\section{INTRODUÇÃO}

Dentre as alternativas que podem ser utilizadas para uma maior sustentabilidade no manejo agrícola, destaca-se a utilização de bioinseticidas, que são inseticidas produzidos com produtos naturais, tanto de origem animal como vegetal, esta última, de grande valia especialmente para agricultores familiares. Esses bioinseticidas tornam-se importantes para esta categoria agrícola, pois são de produção relativamente fácil e de baixo custo, principalmente, a partir de extratos vegetais.

A A. indica vem se destacando, pois inseticidas à partir de seus extratos apresentam baixo custo, e são produzidos de forma bastante simples se comparado com a produção de agrotóxicos e, além de tudo, são considerados menos poluentes, com baixo poder residual e menor risco de intoxicação para mamíferos e aves (QUINTELA \& PINHEIRO, 2004).

Diante do exposto, o presente trabalho reunirá informações sobre a utilização de bioinseticidas na cultura do quiabeiro, podendo contribuir para o controle de insetos-pragas e redução dos custos de produção, fornecendo alternativas de controle para o agricultor familiar.

\section{MATERIAL E MÉTODOS OU METODOLOGIA}

Será testada a eficiência do controle de três tratamentos bioinseticidas e uma testemunha: T1 - Testemunha (água pura), T2 - Óleo comercial puro de Nim, T3 - Extrato aquoso de folhas de nim à $75 \mathrm{~g} / \mathrm{L}$ e T3 - Extrato aquoso de folhas de nim à $150 \mathrm{~g} / \mathrm{L}$. O delineamento experimental será o blocos inteiramente casualizados, com 4 tratamentos (T1, T2, T3 e T4) e 4 repetições (16 plantas/parcela). Cada bloco terá dimensões de $3 \mathrm{~m} \times 21 \mathrm{~m}$, separados entre si por $3 \mathrm{~m}$ lineares. O T2 será o óleo comercial da marca CODIPA diluído a concentração de uso de $1 \%$.

Para testar o potencial inseticida da $A$. indica serão utilizados extratos obtidos através da solução formada por $75 \mathrm{~g}$ e $150 \mathrm{~g}$ de folhas secas, trituradas e diluídas em 1 litro de água (T3 e T4 respectivamente). Para o processo de produção deste composto será feito a 
coleta das folhas, que posteriormente serão postas para secagem à sombra por um período de dez dias até ficarem desidratadas e quebradiças. Logo após será feito a separação de talos e folhas, e estas serão trituradas até obtenção do pó que será utilizado como soluto na solução bioinseticida (VIANA et al. 2006). As soluções inseticidas e a água (testemunha) serão aplicadas quinzenalmente em Abelmoschus esculentus após o décimo dia da emergência das primeiras folhas das plantas.

\section{RESULTADOS E/OU DISCUSSÃO}

Foi observado que as principais pragas que acometeram o cultivo do quiabeiro, foram àquelas tidas como principais da espécie descritas por Moura e Guimarães (2014), tais como vaquinhas (Allocolaspis brunnea Jacoby e Diabrotica speciosa), diferentes espécies de ácaros e cigarrinhas-verde (Empoasca kraemeri Ross \& Moore), com destaque para maiores e mais persistentes presenças de pulgões-do-algodoeiro (Aphis gossypii Glover) e moscas-branca (Bemisia Tabaci), sendo esses dois últimos presentes em todas as avaliações realizadas, tanto em pré, quanto pós aplicações.

Após a primeira aplicação, com dados dispostos na tabela 1, houve um decréscimo na presença de insetos-pragas em alguns dos tratamentos, diferindo-se inclusive da testemunha, com o tratamento 2 (óleo comercial) apresentando menor média de presença de insetos, mas não diferindo significativamente dos tratamentos com concentrações de 75 g/L e 150 g/L de folhas secas de $A$. indica. Na análise dos dados da tabela 1 ainda podemos observar um incremento no grau de infestação de insetos por folha da testemunha da pré-aplicação quando comparada com a pós-aplicação. Essa maior concentração pode ser explicada pela fuga dos insetos para plantas com ausência de biopesticidas, o que pode denotar um poder repelente dos mesmos.

Tabela 1 (inicial). Média \pm Desvio padrão da presença de insetos-pragas em pré e pós primeira aplicação dos tratamentos

\begin{tabular}{ccc}
\hline Tratamentos & Pré-aplicação & Pós-aplicação \\
\hline & $\begin{array}{c}\text { Média } \pm \text { Desvio } \\
\text { padrão }\end{array}$ & $\begin{array}{c}\text { Média } \pm \text { Desvio } \\
\text { padrão }\end{array}$ \\
\hline Trat 1 & $3,81 \pm 1,87 \mathrm{Aa}$ & $6,06 \pm 1,44 \mathrm{Ab}$ \\
Trat 2 & $4,63 \pm 2,06 \mathrm{Aa}$ & $1,25 \pm 1,06 \mathrm{Bb}$ \\
Trat 3 & $5,44 \pm 2,42 \mathrm{Aa}$ & $2,94 \pm 1,91 \mathrm{Bb}$ \\
Trat 4 & $4,31 \pm 2,70 \mathrm{Aa}$ & $1,88 \pm 1,36 \mathrm{Bb}$ \\
\hline * Letras maiúsculas iguais na mesma coluna as médias não diferem \\
significativamente pela prova de Kruskal-Wallis(p>0,05). \\
* Letras minúsculas iguais na mesma linha as médias não diferem \\
significativamente pela prova de Wilcoxon (p>0,05).
\end{tabular}

Houveram seis análises de pré e pós aplicação, onde foram obtidos dados para comparação. É perceptível que na última pré aplicação (Tabela 2.), em média, a presença de insetos-pragas foi menor se comparado com a primeira aplicação, o que pode estar relacionado com o efeito protetor dos bioinseticidas a base de nim, mantendo a planta protegida, apesar do seu baixo poder residual (SILVA, 2009). Os princípios ativos da planta de nim também possuem efeito repelente e diminuem a oviposição dos insetos (NEVES e NOGUEIRA, 1996). É notada então uma constante diminuição na presença dos insetos-praga nas plantas de quiabeiro no decorrer do experimento. 
Tabela 2 (final). Média \pm Desvio padrão da presença de insetos-pragas em pré e pós aplicação dos tratamentos

\begin{tabular}{ccc}
\hline Tratamentos & Pré-aplicação & Pós-aplicação \\
\hline & $\begin{array}{c}\text { Média } \pm \text { Desvio } \\
\text { padrão }\end{array}$ & $\begin{array}{c}\text { Média } \pm \text { Desvio } \\
\text { padrão }\end{array}$ \\
\hline Trat 1 & $5,44 \pm 1,21 \mathrm{Aa}$ & $5,25 \pm 1,13 \mathrm{Aa}$ \\
Trat 2 & $3,13 \pm 1,03 \mathrm{Ba}$ & $1,88 \pm 0,72 \mathrm{Bb}$ \\
Trat 3 & $2,81 \pm 0,66 \mathrm{Ba}$ & $1,19 \pm 0,75 \mathrm{Cb}$ \\
Trat 4 & $2,19 \pm 0,98 \mathrm{Ca}$ & $0,44 \pm 0,51 \mathrm{Db}$ \\
\hline
\end{tabular}

* Letras maiúsculas iguais na mesma coluna as médias não diferem significativamente pela prova de Kruskal-Wallis( $\mathrm{p}>0,05)$.

* Letras minúsculas iguais na mesma linha as médias não diferem significativamente pela prova de Wilcoxon $(\mathrm{p}>0,05)$.

Percebe-se que na quarta aplicação ocorreu uma nova fuga dos insetos dos tratamentos com presença de inseticidas para a testemunha, demonstrando o potencial repelente desses extratos presentes nos demais tratamentos. Houve também o surgimento de insetos auxiliares no controle de pragas, como as joaninhas (Coleomegilla sp.), que de acordo com Oliveira et al (2004), se alimentam comumente de populações de insetos como pulgões, diminuindo seus números e reduzindo os danos causados pelos mesmos.

\section{CONSIDERAÇÕES FINAIS}

Tanto as concentrações com 75 e $150 \mathrm{~g} / \mathrm{L}$, quanto o óleo comercial de nim, demonstraram eficiência significativa no controle de insetos-pragas em plantas de quiabeiro.

Ao fim das aplicações o tratamento $4(150 \mathrm{~g} / \mathrm{L})$ mostrou $(\mathrm{p}<0,05)$ a menor taxa de incidência de insetos, demonstrando ser mais eficaz, portanto, uma alternativa absolutamente viável para ação antagônica à insetos-praga desta cultura.

\section{REFERÊNCIAS}

DE OLIVEIRA, N. C.; WILCKEN, C. F.; DE MATOS, C. A. O. Ciclo biológico e predação de três espécies de coccinelídeos (Coleoptera, Coccinellidae) sobre o pulgão-gigante-dopinus Cinara atlantica (Wilson) (Hemiptera, Aphididae). Rev. Bra. de Entomologia, p.529533, dez. 2004.

NEVES, B. P.; NOGUEIRA, J. C. M. Cultivo e utilização de nim indiano (Azadirachta indica A. Juss. ). Goiânia, EMBRAPA-CNPAF, v.39, Cir. Téc., 28. 1996.

QUINTELA, E. D. \& PINHEIRO, P. V. 2004. Efeito de extratos botânicos sobre a oviposição de Bemisia tabaci biótipo $\mathbf{B}$ em feijoeiro. Comunicado Técnico 92, Embrapa Arroz e Feijão, Santo Antônio de Goiás, GO, p.6.

SILVA, M.S. Atividade inseticida de folha e da torta da semente de nim Azadiratchta indica A. Juss no controle de Spodoptera frugiperda em milho (Zea mays L.). Alagoas, 2009. Dissertação.

VIANA, P. A; PRATES, H. T; RIBEIRO, P. E. A. Uso do Extrato Aquoso de Folhas de NIM para o Controle de Spodoptera frugiperda na Cultura do Milho. EMBRAPA Milho e Sorgo. Sete Lagoas-MG. Circular Técnica, número 88, 2006. 